\title{
Vidas após a cirurgia de redesignação sexual: sentidos produzidos para gênero e transexualidade
}

\author{
Life after sexual reassignment surgery: significance for gender and \\ transsexuality
}

Pablo Cardozo Rocon (https://orcid.org/0000-0003-2696-5786) ${ }^{1}$

Francis Sodré (https://orcid.org/0000-0003-4037-9388) ${ }^{2}$

Alexandro Rodrigues (https://orcid.org/0000-0002-5998-4978) ${ }^{3}$

Maria Elizabeth Barros de Barros (https://orcid.org/0000-0003-1123-4374) ${ }^{4}$

Getulio Sérgio Souza Pinto (https://orcid.org/0000-0002-0478-5322) ${ }^{5}$

Maria Carolina Fonseca Barbosa Roseiro (https://orcid.org/0000-0001-6817-2296) ${ }^{4}$

\footnotetext{
${ }^{1}$ Instituto de Saúde Coletiva, Universidade Federal de Mato Grosso. Av. Fernando Corrêa 2367, Boa

Esperança, Bloco CCBSIII, 2o piso. 78060-900 Cuiabá MT Brasil. pablocardoz@gmail.com ${ }^{2}$ Programa de PósGraduação em Saúde Coletiva, Universidade Federal do Espírito Santo (UFES). Vitória ES Brasil. ${ }^{3}$ Programa de PósGraduação em Psicologia Institucional, UFES. Vitória ES Brasil.

${ }^{4}$ Programa de PósGraduação em Educação, UFES. Vitória ES Brasil. ${ }^{5}$ Hospital Universitário Cassiano Antônio de Moraes, UFES. Vitória ES Brasil.
}

\begin{abstract}
The Transsexualization Process is the main service directed to trans-specific health in Brazil, which provides services such as hormone therapy and sexual reassignment surgeries to the trans population. In this article, the significance surrounding the surgical procedure, the new genitalia, gender and transsexuality among women who underwent sexual reassignment surgery at the Cassiano Antonio de Moraes University Hospital (HUCAM), located in Vitória, Espirito Santo State, Brazil, was analyzed. Qualitative research was carried out, narrative interviews were recorded, and thematic content analysis was performed. The sample was composed of 9 participants selected by snowball sampling. The conclusion drawn is that the surgeries are related to the search for the humanization of bodies. The comprehension about being a woman was not limited to a biological status for gender. Transsexuality was presented as a transitional experience between genders. The sexual reassignment surgery was seen as a strategy of corporal correction in line with expectations about social relationships in gender by participants, the success of which is evaluated from the standpoint of beauty, pleasure and passability.
\end{abstract}

Key words Sexual reassignment surgery, Genitals, Gender, Transsexuality, Passability
Resumo O Processo Transexualizador é o principal serviço direcionado à saúde trans-específica no Brasil, o qual oferta aquisições como hormonioterapia e cirurgias de redesignação sexual à população trans. Neste artigo, analisaram-se os sentidos produzidos em torno do procedimento cirúrgico, da nova genitália, sobre gênero e transexualidade entre mulheres que realizaram cirurgia de redesignação sexual no Hospital Universitário Cassiano Antônio de Moraes (HUCAM), localizado em Vitória, Estado do Espírito Santo, Brasil. Foi realizada pesquisa qualitativa com entrevistas narrativas gravadas em áudio, e realizada análise de conteúdo. Foram selecionadas 09 participantes a partir da metodologia bola de neve. Conclui-se que as cirurgias estão relacionadas à busca pela humanização dos corpos. As compreensões sobre ser mulher não se limitaram a um estatuto biológico para os gêneros. A transexualidade foi apresentada como uma experiência de transição entre os gêneros. A cirurgia de redesignação sexual foi apontada como estratégia para a construção de um corpo em consonância com a experiência das participantes nas relações sociais de gênero, cujo sucesso é avaliado sob signos de beleza, prazer e passabilidade.

Palavras-chave Cirurgia de redesignação sexual, Genitália, Gênero, Transexualidade, Passabilidade 


\section{Introdução}

O Processo Transexualizador é um importante serviço em saúde para a população trans que vislumbra intervenções cirúrgicas e hormonais. Entretanto, como o nome sugere, construir-se no gênero é um processo cujos sentidos não devem centrar-se nas cirurgias de redesignação sexual ${ }^{1}$.

Ao longo das vidas Cisgênero (que não apresentam divergência com o gênero atribuído no nascimento) ou Transgênero, todos constroem seus corpos para viver as relações sociais em seus entrecruzamentos com dispositivos de normalização e tecnologias de produção do gênero ${ }^{2-4}$. Sociabilidades que se materializam como regramentos generificados, segundo os quais "a instituição de uma heterossexualidade compulsória e naturalizada exige e regula o gênero como uma relação binária em que o termo masculino diferencia-se do termo feminino, realizando-se essa diferenciação por meio das práticas e do desejo sexual"5(p.45).

Há que se afirmar, entretanto, que as mulheres que vivenciam a transexualidade em suas vidas apresentam particularidades, dentre os quais destaca-se: o acesso desigual aos recursos médico-farmacológicos para modificação dos corpos, e o não reconhecimento de suas vidas na matriz de inteligibilidade para humano ${ }^{2-5}$. $\mathrm{Na}$ medida em que as normas que produzem os sentidos sobre humanidade e abjeção o fazem recortadas por compreensões essencialistas sobre homens e mulheres produzidos pela presença ou ausência do pênis ou vagina, desloca-se as vidas que se experienciam em transexualidades de humanos para o campo da abjeçãoo ${ }^{3,4}$.

Neste artigo, analisar-se-á as compreensões sobre gênero e transexualidade, bem como os sentidos para a nova genitália e para a cirurgia de redesignação sexual produzidos por mulheres que realizaram o referido procedimento.

\section{Metodologia}

Tendo em vista os objetos em análise - sentidos atribuídos à nova genitália, a avaliação da cirurgia de redesignação sexual e as compreensões sobre 'ser mulher' - foi realizada pesquisa com abordagem qualitativa, compreendendo os sentidos como "produtos das interpretações que os humanos fazem a respeito de como vivem, constroem seus artefatos e a si mesmos, sentem e pen$\operatorname{sam}^{\prime 6}($ p.57).

A produção dos dados teve como instrumento entrevistas narrativas gravadas em áudio, com tempo médio de 36,6 minutos. Segundo Castellanos 7 , "a narrativa é considerada uma forma universal de construção, mediação e representação do real que participa do processo de elaboração da experiência $\operatorname{social}^{\prime \prime}(p .1068)$. Foi realizada análise de conteúdo temática ${ }^{6}$ do material, organizando e selecionando o conteúdo transcrito a partir de eixos de sentido baseados nos objetos em análise.

Foram entrevistadas 9 (nove) participantes no período de janeiro a junho de 2017 , selecionadas pela metodologia bola de neve, seleção "probabilística, que utiliza cadeias de referência. Ou seja, a partir desse tipo específico de amostragem não é possível determinar a probabilidade de seleção de cada participante na pesquisa, mas torna-se útil para estudar determinados grupos difíceis de serem acessados"8(p.203).

A partir dos contatos telefônicos disponíveis no Hospital Universitário Cassiano Antônio de Moraes (HUCAM), fora sorteada a primeira entrevistada. As demais entrevistas se deram por indicações oferecidas nas entrevistas realizadas. Contatou-se 19 mulheres a partir das indicações, entretanto 10 recusaram a entrevista por residirem em outros estados ou pela indisponibilidade em narrar seu passado. Rocon ${ }^{4}$ e Hess et al. ${ }^{9}$ relatam dificuldades em contatar mulheres após a realização das cirurgias de redesignação sexual, evidenciando que muitas mudam de endereço ou não se disponibilizam a narrar seu passado quando a cirurgia de redesignação sexual é considerada bem sucedida por elas, apontando inclusive a tentativa de desvincular-se do passado como parte do processo de transição no gênero.

O critério estabelecido para seleção das participantes para as entrevistas foi o fato de serem mulheres que passaram pela cirurgia de redesignação sexual no HUCAM, hospital referência para tal serviço no Espírito Santo. O Conselho Federal de Medicina e o Ministério da Saúde determinam que no Brasil, sejam eleitas aos serviços transexualizadores apenas pessoas com diagnóstico de transexualismo, concedido após acompanhamento mínimo de dois anos no processo transexualizador por equipe composta por médico cirurgião, psiquiatra, endocrinologista, psicólogo e assistente social ${ }^{10,11}$. Os critérios para diagnóstico são: "Art. 3o[...]: 1) Desconforto com o sexo anatômico natural; 2) Desejo expresso de eliminar os genitais, perder as características primárias e secundárias do próprio sexo e ganhar as do sexo oposto; 3 ) Permanência desses distúrbios de forma contínua e consistente por, no mínimo, dois anos; 4) Ausência de outros transtornos mentais" ${ }^{\prime 10}$. 
O critério de inclusão foi estabelecido em busca da superação de um importante limitador para a pesquisa: pacientes em acompanhamento no processo transexualizador estão sob o estresse de conseguirem os laudos necessários para acessarem os serviços. Nesse sentido, podem apresentar receio em compartilhar os sentidos que produzem sobre gênero, transexualidade, a patologização e do próprio processo de diagnóstico, quando aqueles divergem dos sentidos esperados pela equipe envolvida no processo de diagnóstico. Receio de que tais informações possam prejudicar o alcance dos laudos necessários para acessarem os serviços em saúde.

A pesquisa foi aprovada pelo Comitê de Ética em Pesquisa da Universidade Federal do Espírito Santo e a participação consentida a partir do Termo de Consentimento Livre-Esclarecido (TCLE). Como necessidade de garantia do anonimato, a fim de não identificar as narradoras, não são apresentados nomes, bem como não é realizada caracterização das narradoras.

\section{Resultados e discussão}

\section{Tenho vagina, logo existo?}

Eu sou mulher e fim de papo. Eu tenho como provar! Tenho buceta, tenho documentos registrados, tudo certinho! (Participante 9).

Esse excerto de narrativa tem em seu contexto a inconformação com situações em que é negado a participante o reconhecimento da existência como mulher. "Eu tenho como provar!", exclamou a participante, e as justificativas apresentadas são a presença de uma genitália - "Tenho buceta" - e as normas jurídicas - "tenho documentos registrados" - que deveriam servir de prova jurídico-biológica da sua existência como mulher.

Butler $^{12}$ aponta que a existência é desdobramento do reconhecimento de uma vida a ser protegida, passível de luto, que importe nos ciclos de afeto provocando movimentos políticos para sua proteção, acolhimento e manutenção. Foucault provoca a pensar que existir é ser recortado pelo racismo de estado ao fazer viver ${ }^{13}$, é ter as condições de precariedade da vida minimizadas ${ }^{12}$.

Nesse sentido, podemos afirmar que a participante 9 não existe quando o reconhecimento é concebido como condição à existência. Contudo, ela resiste, re-existe no sentido de uma produção de experiências com a existência a partir da reconstrução de si no corpo e nas palavras, a partir de reinvenções. Esse processo permite a criação de novas dimensões normativas que argumentem pró sua existência, não necessariamente formatadas pelo gênero binário: "produz a ideia de que o gênero reflete, espelha, o sexo [...] a natureza constrói as sexualidades e posiciona os corpos de acordo com as supostas disposições naturais" ${ }^{\prime 4}$ (p.90).

Outras participantes trazem em suas narrativas momentos em que 'a verdade de seus corpos' é questionada, e assim, o reconhecimento de sua existência:

Acontece muito isso. De um homem se encantar com a minha pessoa e não saber do meu passado. Quando ele for deitar comigo, se for um relacionamento duradouro, eu vou ter que contar pra ele, ou alguém vai contar de fofoca. - 'É um viado operado. Te enganou' (Participante 7).

Tudo que falava como 'ele' comigo me ofendia. Eu tinha aquela coisa de que eu era mulher, mas, sabendo que eu não era de verdade. Eu tinha um órgão masculino. Então, aquilo ali me afetava muito, eu ficava triste, eu chorava muito. Então querendo ou não as pessoas elas têm sempre que apontar aquilo ali, então eu acho que hoje isso mudou e ajudou muito. Entendeu? Não que o preconceito não existe, ele existe ainda, mas que diminuiu muito (Participante 8).

Pra te falar a verdade socialmente não mudou nada, porque eu continuo né... Agora, pessoalmente mudou, porque eu estou feliz por ter conseguido. Pessoalmente falando eu estou muito feliz. Agora, não mudou nada, assim, as pessoas me vêem como um Trans, um Travesti, do mesmo jeito. Não mudou nada (Participante 4).

A humanização do corpo pode ser afirmada como elemento central na motivação que atravessa a procura pelos serviços transexualizadores. Humanização é aqui compreendida, em diálogo com Butler ${ }^{12}$ e Bento ${ }^{14}$, como a busca pelo reconhecimento desse corpo, deslocando-o da abjeção ao estatuto de humano pela adequação das estruturas físico-corporais às normas para gênero e sexualidade. O desejo por reconhecimento das vidas e existências, por uma vida sem discriminação, sem o sofrimento oriundo das interpelações das normas de gênero parece as conduzir a procurar pelo processo transexualizador.

Contudo, as narrativas sobre as experiências advindas das interações sociais pós-processo transexualizador, vão mostrando que a cirurgia de redesignação sexual e a hormonioterapia parecem insuficientes para garantir o reconhecimento. As participantes continuaram tendo a 'verdade de seus corpos' questionada, passando inclusive a 
serem apontadas como uma imitação. Elas possuem seios, vagina, doses corporais de estrogênio, dentre outros elementos biológicos requeridos à classificação das mulheres. Contudo, mesmo após a transição completa, as mulheres dessa pesquisa continuaram tendo seu estatuto de gênero questionado. São comuns histórias de relacionamento que terminaram após a descoberta do passado pelo parceiro, bem como dificuldades em se relacionar; histórias em que as participantes foram apontadas como mulheres falsas antes da cirurgia por não terem vagina, e, após a cirurgia de redesignação sexual, apontadas novamente como imitação, ou até mesmo monstruosidades, desvencilhando-as das possibilidades de humanização dos corpos frente ao gênero binário.

Segundo Foucault 15 , "podemos dizer que o que faz a força e a capacidade de inquietação do monstro é que, ao mesmo tempo em que viola a lei, ele a deixa sem voz. Ele arma uma arapuca para a lei que esta infringindo"15(p.48). O autor discorrerá que o monstro em sua constituição viola as leis jurídicas (normas jurídicas da sociedade) e a leis da natureza (biológicas), de forma que ao monstro cabe uma dupla infração numa sociedade regulamentada por normas jurídicobiológicas.

Foucault ${ }^{15}$ dirá que o anormal, até o final dos séculos XIX ou XX, fora visto como um monstro cotidiano, banalizado, e que o monstro, "combina o impossível com o proibido"15. Quando se toma as experiências narradas como fios de análise, pode-se supor como o lugar da impossibilidade normativa - tornar-se mulher a partir das alterações biológicas, estruturais e fenotípicas do corpo; e como proibido - a infração das normas de gêneros. Nesse sentido, a combinação entre impossível e proibido constitui-se em paradoxal potência de criação, na medida em que as normas jurídicas - leis, manuais de diagnóstico, portarias, etc - que deveriam selar os corpos pela biologia, são as que permitiram a quebra do selo biológico dos corpos para alterá-los em direção ao aparente impossível: ser/tornar-se mulher sem ter nascido com uma vagina.

Nessas reflexões, ao monstro por anunciar ser possível resistir, por contornar e criar normas para viver e manipular os corpos cabe a não existência, quando essa é compreendida como reconhecimento. Como aberração, seu estatuto será de abjeto, ameaça à existência por anunciar a re-existência. O monstro pode ser, desse modo, a anunciação de diferentes possibilidades de vidas, o anúncio de outras normatividades para a existência. Por esse viés, a transexualidade pode ser a armadilha das normas jurídico-biológicas que negam a existência de vidas em dissonância com a heterossexualidade compulsória e o gênero binário. $\mathrm{O}$ trânsito nos gêneros é a prova em vida das possibilidades de manipular a biologia dos corpos produzindo normatividades e anunciando possibilidades não previstas de existência.

Mas se as participantes dessa pesquisa aparentam buscar adequarem-se às normas hegemônicas para o gênero, como poderiam ocupar o lugar da transgressão? Butler ${ }^{4}$ aponta que mesmo quando se busca adequar os corpos às normas de gênero, o processo de transição de gênero denuncia as essencializações normativas. Essa talvez seja, em diálogo com Foucault ${ }^{15}$, a armadilha da transexualidade para as normas de gênero, que ao romper o selo normativo-biológico para transformação dos corpos em função da produção de uma coerência entre corpo, genitália e normas, revelam a ficção da naturalização dos gêneros.

Ainda que as participantes vislumbrem adequar seus corpos ao estatuto bio mulher de gênero, no trânsito corpóreo que realizam, dilaceram não apenas a fixação dos gêneros aos corpos por pressupostos biológicos, como vão revelando que a plasticidade do corpo também é potência de re -existência. O trânsito corpóreo revela um corpo cujas fronteiras para produção de uma existência são maleáveis, e que a biologia não é um fim em si mesma, mas o começo da possibilidade de manipulação e transformação de corpos, produzindo novas normas para experimentar-se.

Contudo, apesar da monstruosidade ser vislumbrada aqui como campo de possibilidade para produção de uma vida com novas normas, justamente por anunciar a re-existência esse lugar é perseguido e, de fato, não muito desejado. Assim, desvincular-se das figuras do monstro, anormal e transgressor, no caso da transexualidade, supõe intervir nos corpos a fim de alcançar o reconhecimento e a inteligibilidade como humano no próprio terreno normativo o qual a condição trans desloca.

\section{Sentidos atribuídos à vagina e à cirurgia de redesignação sexual}

A Resolução CFM 1.955/2010 significa a transexualidade como "desvio psicológico permanente de identidade sexual, com rejeição do fenótipo e tendência à automutilação e/ou autoextermínio" ${ }^{10}$, tomando o gênero como categoria patológica. Nesse sentido, criam-se os gêneros saudáveis (binários e heteronormalizados), os gêneros doentes (anormais e monstros). 
Nesse contexto do gênero-patologia, o pênis da mulher é construído como disfunção, tendo em vista que para o gênero saudável mulher possui vagina. A população trans, dessa maneira, é colocada no campo dos transtornos de identidade, das disforias e desordens mentais, que facilmente poderíamos traduzir por disfunções de gênero.

Esse processo evidencia a produção paródica do gênero, em que se cria um gênero original dito saudável e os gêneros que seriam as cópias chamados desvios. Entretanto, afirma-se aqui, em consonância com Butler ${ }^{5}$, a inexistência da relação original-saudável e cópia-desvio, tendo em vista que: "a repetição imitativa do original revela que o original nada mais é do que uma paródia da ideia de natural"s(p.57). Assim, ambos se constituem em performances imitativas das normas jurídico-biológicas para os gêneros.

Tais normas tomam o gênero como categoria sócio-bio-política, de maneira que sua medicalização será um ato eminentemente técno-político-normativo: técno porque a produção do gênero é tecnológica, na medida em que o fazemos com hormônios e procedimento estéticos e cirúrgicos ${ }^{3}$; político tendo em vista que gênero é engendrado em mecanismos, dispositivos e biopolíticas de controle e administração da vida ${ }^{3,5,13}$, normativo uma vez que se produzem normas no exercício de viver e tais normas são contextuais do ponto de vista sócio-político, histórico, geográfico e cultural ${ }^{16}$.

As normas e as noções de saúde e adoecimento seguem os mesmos determinantes para o gênero - "O indivíduo é doente segundo a classificação de sua sociedade e de acordo com os critérios e modalidades que ela fixa. Isto implica que o saber médico também está intimamente articulado com o social" ${ }^{17}$ (p.103). Observando os serviços transexualizadores sob essa perspectiva, poder-se-á afirmar que a hormonioterapia e cirurgias de redesignação sexual são apresentadas como caminhos terapêuticos ao tratamento da transexualidade como pontuam as normati$\mathrm{vas}^{10,11}$, uma vez que num contexto sócio-político em que "normas predominantes para a inteligibilidade dos corpos residem no gênero binário e na heteronormatividade, todos os corpos inadequados a esse padrão poderão ser considerados doentes, como no caso dos corpos trans"18 (p.2524).

Por esse motivo, faz-se necessário buscar os sentidos atribuídos aos serviços transexualizador pela população usuária. Eles podem ser estratégicos para criar novos mecanismos de acompanhamento da população trans nos serviços de saúde, tendo em vista que a patologização tem impedido o acesso à parte das mulheres trans $\mathrm{s}^{4,14,18-22}$ ao atendimento adequado às suas demandas. Vejamos algumas narrativas:

Eu me sinto mulher hoje. Com a vagina. Porque tem penetração. E eu sinto prazer. [...] Porque eu já ouvi mulher falar comigo assim: "Ah! Eu tenho vagina". E eu ir lá e ficar com o marido dela sem nem ela saber (risos). [...] e ele sabendo de toda a história. (Participante 7).

Eu me sinto mais mulher depois da cirurgia. Eu me sinto mais confiante, eu me sinto mais livre, eu me sinto mais confortável. Antes eu não ficava pelada na frente de ninguém, hoje eu já fico. (Participante 6).

Na minha cabeça eu já era mulher. Eu me tornei mulher pra me relacionar com outras pessoas. Aí eu acho que as pessoas, os homens, começam a me enxergar de outra maneira. A minha cabeça era essa. Mulher. Sempre fui. Tanto é que me incomodava ter o pênis no meio das pernas. Oh! Como eu sofri com aquele pênis, na hora sexual, e também na hora de guardar. Doía. [A cirurgia] É por causa dessas questões culturais, e o fetiche também do homem, que tem né. Pelo homem não entender que transexual é transexual e travesti é travesti. (Participante 5).

As participantes apontam a redesignação sexual como ampliadora das possibilidades de afirmarem-se e de socializar seus corpos como mulheres. Em algumas narrativas é possível perceber que o estatuto de mulher não é tratado como uma condição biológica pré-existente, mas como um projeto/desejo:

Cheguei a pensar, anteriormente, que eu era mais especial do que as mulheres em geral. Por quê? [...] Eu nasci um menino e me tornei essa mulher. Eu conheço mulheres que não são mulheres. Que não têm essa vontade de ser mulher. (Participante $1)$.

Ser mulher, nesse sentido, localiza-se no campo dos desejos, afetos, projetos e intenções, de modo que é pelo desejo de ser, mais do que a presença de uma genitália congênita, que se constitui mulher. Pelos desejos mudam-se os corpos, comportamentos, produz-se uma mulher.

O componente sociopolítico ${ }^{3,4,19,20}$ é determinante na avaliação que as participantes realizam sobre a necessidade da cirurgia em suas vidas, bem como os benefícios de ser uma mulher com vagina. Todas as mulheres entrevistadas estão sob as mesmas expectativas de uma vida no gênero binário a que estão sujeitas as mulheres cisgênero, com padrões de comportamento, desejos, beleza e sonhos para uma vida gendrada ${ }^{18,19}$. Com 
a vagina, elas podem acessar toda documentação jurídica com nome e gênero que desejam, como pontuou a Participante 9:

Tão bom ter seu passaporte de mulher. Essas coisas todas [demais documentações]. Eu me sinto realizada. [...] Eu me sinto uma mulher.

Os documentos são importantes mediadores nas relações sociais e têm sido determinantes do acesso aos serviços de saúde pela população trans ${ }^{18,19}$.

As relações sexuais ganham destaque, de modo que as palavras penetração e prazer destacam-se na produção de sentidos sobre ser mulher. A participante 7 afirma seu corpo mulher relatando as relações sexuais com um parceiro casado com uma mulher cisgênero. Ela demarca ainda que são relações sexuais com "ele sabendo de toda a história", tomando esse encontro como um avaliador do sucesso da cirurgia de redesignação sexual.

A participante 5 ao dizer "e aquela travesti não podia dar o que ele queria [o pênis]. Era o pênis o meu problema", relata que muitos homens ao procurá-la para relações sexuais antes da cirurgia o faziam com interesse em inserir o pênis nas relações sexuais, algo que para ela a deslocava à categoria identitária travesti, da qual buscava se desvincular. Nessa direção, relatou a ojeriza no uso de seu pênis nas relações sexuais como principal marcador de diferença entre travestis e transexuais.

Outro elemento que precisa ser destacado é o fato da cirurgia permitir, para as mulheres, a apresentação pública do corpo: "Eu me sinto mais confiante, eu me sinto mais livre, eu me sinto mais confortável”, "antes eu não ficava pelada na frente de ninguém, hoje eu já fico", "Oh! Como eu sofri com aquele pênis, [...] e também na hora de guardar. Doía. Não era agradável". A ausência do pênis, nessa direção, não pode ser resumida a um sentido 'mulher de verdade' pela presença de uma vagina, mas, para elas, como possibilidade de socializar-se com o corpo nas relações de gênero, inclusive considerando o que nesse contato social é o toque consigo mesmo. Sem o pênis a nudez é possibilidade, bem como o uso de determinadas roupas sem a necessidade das estratégias doloridas e desconfortáveis para esconder o pênis.

Aponta-se ainda importante divergência entre as concepções sobre gênero-patologia e, assim, os sentidos para a cirurgia de redesignação sexual e para a vagina construídos pelas participantes. Nenhuma participante apontou a transexualidade como condição patológica, narrandose doentes nos termos descritos pela Resolução $\mathrm{n}^{\mathrm{o}} 1.955^{10}$, bem como não descreveram a cirurgia de redesignação sexual como tratamento:

Eu não me sentia doente, eu me sentia incompleta. [...] eu não sei explicar, era uma falta, não era doença. Muitas Travestis estão usando a palavra Trans, porque Trans está associado à doença, a cuidado... é mais aceito. (Participante 6).

Eu acho que a cirurgia ajudou a consertar uma coisa que a natureza negou. Que a mãe natureza [...] deixou pra a gente aprender. Eu acho doença um nome um pouco pesado. [...] Mas eu acho que eles põem doença porque quando se fala em doença o preconceito diminui. (Participante 7).

Durante o acompanhamento pré-cirurgia no processo transexualizador, as participantes precisaram se identificar como doentes para acessarem os serviços oferecidos. A literatura científica tem mostrado que a capacidade de performatizar a figura da transexual de verdade, que reproduz as normas de gênero performatizando estereótipos de mulher de verdade e desvinculase da travestilidade tem sido determinante para aprovação no processo de diagnóstico ${ }^{4,14}$. Bento ${ }^{14}$ pontua que "o único mapa que guia o olhar médico e dos membros da equipe são as verdades estabelecidas socialmente para os gêneros. Não existe um só átomo de neutralidade. Estamos diante de um poderoso discurso que tem como finalidade manter os gêneros prisioneiros à diferença sexual"14 (p.87).

Todavia, ao serem questionadas sobre o sentido do procedimento cirúrgico e da transexualidade, as participantes indicam a cirurgia como correção, não no sentido tratamento para algum desvio, mas em direção à produção de uma coerência com as expectativas que elas constroem sobre viver e experimentar seus corpos nas relações de gênero.

A transexualidade associada à doença, na percepção das participantes, serve à redução do preconceito e da discriminação. Esse relato revela que o uso da patologização da transexualidade não é apenas estratégia para acessar os serviços transexualizadores como mostram estudos ${ }^{18-20}$, mas também como dispositivo para produção de reconhecimento de outras pessoas com suas vidas. Bento e Pelúcio ${ }^{21}$ apontam o uso do discurso de patologização pelo movimento social como estratégia para garantir a oferta dos serviços transexualizadores via SUS.

Rocon et al. ${ }^{19}$, ao distinguirem as compreensões sobre saúde e adoecimento entre pacientes trans e profissionais dos serviços transexualizadores, concluíram que para a população trans "as transformações corporais constituem processos 
de produção de saúde, explorando a plasticidade de seus corpos como potência de vida, mediada pelos ideais de beleza"19(p.531), enquanto para os profissionais da saúde significaram tratamento e cura.

Para as participantes, transexualidade não é doença, mas um lugar de passagem. A cirurgia não é compreendida como tratamento, mas correção de algo que não está em sintonia com as expectativas que elas constroem sobre seus corpos. Expectativas mediadas por normas, dispositivos e tecnologias de controle, normalização e produção dos gêneros.

\section{As relações afetivo-sexuais como campo de experimentação e avaliação do corpo construído com o processo transexualizador}

A relação com o outro é um importante analisador de signos de beleza entre todas as pessoas $^{19}$. Enchem-se as academias, clínicas de estética, salões e barbearias em função da construção de um corpo a ser socializado, avaliado sob signos de beleza construídos e postos nos ciclos de afetos pela mídia, indústria farmacêutica, etc. Os resultados dos procedimentos estético-cirúrgicos sempre passarão pela avaliação que o outro realiza sob signos de beleza, saúde, etc.

Rocon et al. ${ }^{19}$, analisando os processos de transformação do corpo entre pessoas trans trabalhadoras com sexo, apontou a relação com os clientes, aferida pelos ganhos financeiros, como principal mediador/analisador dos ideais de beleza, feminilidade, saúde, e das escolhas pelos recursos a serem utilizados nas modificações corporais.

Para as participantes desta pesquisa, as relações afetivas e sexuais se apresentaram como importante campo de testagem e experimentação do novo corpo, sendo apresentadas como determinantes nos processos de avaliação sobre a transição no gênero com auxílio dos serviços de saúde:

Tem pessoas que acham que [a mulher trans] não chega ao prazer. Isso é mentira, é mito. Chega sim. Só que assim vai muito do parceiro também. [...] No início da cirurgia você fica meio perdida porque você tem que se acostumar com aquele órgão. (risos) [...] Tudo é a mente. No início eu tive dificuldade devido a me acostumar né. Assim, foi depois de quatro meses que eu comecei a me conhecer mais. (Participante 8)

Só que eu até fiquei com outras pessoas, e passei direto. Entende? Fiquei num vi diferença nenhuma, e eles também não perceberam. Só que tem homens que são espertos. É isso que eu queria saber, porque eu pergunto pro meu marido: Tem diferença? E ele fala que não. Só que eu sou muito curiosa. Entende? [...] na minha cabeça, na hora da penetração, eu acho que vai ter algo diferente. (Participante 8)

A participante 8 possui um casamento que antecede a cirurgia de redesignação sexual. Nesse sentido, para ela, a avaliação do marido é elemento importante, uma vez que este já se relacionou com mulheres cisgênero e vivenciou relações sexuais com ela quando possuía pênis. Contudo, no receio dos sentimentos do marido influenciar sua avaliação, a participante foi experimentar seu corpo na relação com outros homens, a fim de conseguir avaliações de desconhecidos. A participante narra com muita satisfação que "passou direto", traduzido por ela como sucesso da cirurgia de redesignação sexual, bem como, de todo o processo de transição no gênero. $\mathrm{Lanz}^{23}$ discorre que "[...] passar é igual a ser reconhecida e aceita pela sociedade. Quanto mais passável, [...] menor a chance de ser estigmatizada e violentada"23(p.285). A Passibilidade portanto, é uma avaliação que depende do outro e se apresenta como importante analisador do sucesso da transição no gênero.

O prazer também é apresentado como signo de avaliação da transição no gênero. A narrativa marca o prazer não apenas como biológico, posto que este depende do parceiro e da mente. A mente talvez seja o recurso utilizado para afirmar o prazer como aprendizado, dependente do autoconhecimento com a nova genitália e do encontro com o outro. Nesse sentido, o prazer como produto da mente e do encontro, de um processo de aprendizado de si, torna-se elemento de afirmação do sucesso da mulher que produziu. A participante 8 ainda se contrapôs ao que nomeou como o mito de que mulheres as quais fizeram cirurgia de redesignação sexual não experimentam prazer, demarcando mais uma vez a importância do prazer enquanto signo avaliativo.

Contudo, apesar dos relatos sobre o sucesso da cirurgia de redesignação sexual avaliado nos encontros com parceiros, esta também pode apresentar-se como impasse às relações afetivas e sexuais quando não possibilita a passabilidade, dificulta a socialização dos corpos nas relações afetivas e/ou sexuais e não permite boas avaliações sobre signos prazer. Dois impasses foram destacados:

Não tive relação depois dessa cirurgia, porque essa cirurgia ela não está boa. Então, como que eu vou sair com um cara, que de repente é hetero, que de repente aceitou sair com uma Transexual, e de 
repente espera chegar na hora $H$ [...] não tem uma vagina perfeita, tem uma vagina com cicatrizes [...]. Então, assim, é um processo que pra quem é Transexual é muito difícil. Porque você se sente mulher, se vê mulher, o parceiro também, e de repente você tem esse impasse. Então, assim, a relação. A vida sexual hoje. Nem sei tá uma merda! (Participante 6).

Às vezes até atrapalha. Porque tem homens que talvez ficavam com a gente porque tinha o órgão masculino. Agora já perdeu a graça, é isso que eles falam, que se for pra ficar com mulher mesmo eles ficam com quem já nasceu mulher. (Participante 4).

O primeiro impasse está nos resultados estéticos da cirurgia. Há um processo de idealização sobre aspectos estéticos para o corpo-mulher que são atravessados pelas normas de gênero. As mulheres, Cis ou Trans, são cotidianamente interpeladas por signos de beleza não restritos às estruturas que se localizam da cintura para cima ${ }^{3,19}$. Assim como há ideais de seios, lábios, nariz, etc, existem os formatos de nádegas e vagina requisitados belos, aceitáveis e socializáveis. Esperase do processo transexualizador, por esse viés, a construção de uma vagina que, do ponto de vista estético, corresponda aos signos que avaliam os corpos.

A participante 6 narra sua dificuldade em permitir-se ao encontro sexual em virtude de sua vagina apresentar cicatrizes oriundas do processo cirúrgico. A presença das cicatrizes indica que não basta ter uma vagina para ser mulher, é preciso ser reconhecida como uma, processo que parece impedido pelo resultado cirúrgico. É preciso que a genitália seja esteticamente bem avaliada pelo outro, como vagina passável, tal qual a da mulher cisgênero. Importa também que ela seja funcional e tal funcionalidade é avaliada pelo signo do prazer, avalizado no encontro com o parceiro sexual, impossibilitada, nesse caso, pela ausência de passabilidade produzida pelo mal avaliado resultado cirúrgico.

Hess et al. ${ }^{9}$ apontam a aparência e a funcionalidade como indicadores da satisfação com a cirurgia de redesignação sexual male-to-female. Aqui evidencia-se, como Rocon et al. ${ }^{19}$, que o resultado estético da cirurgia de redesignação sexual, aliado aos signos de prazer expostos pela satisfação de parceiros sexuais, foram apontados como justificativas ao sucesso da cirurgia e atravessaram diretamente as avaliações sobre saúde, beleza e adoecimento que as mulheres realizavam sobre si. Além disso, os resultados estéticos terão impacto direto em processos de sofrimento e adoecimento passíveis de surgirem com a cirurgia mal sucedida.

Mulheres podem procurar os serviços transexualizadores são estimuladas por parceiros afetivos e sexuais ${ }^{18,19}$. Nesse sentido, a avaliação destes sobre os resultados do processo ocupa um importante lugar na auto avaliação realizada pelas mulheres redesignadas. Contudo, nesse ponto reside o segundo impasse: a recusa, ou não procura, dos antigos parceiros sexuais por encontros com as participantes. A participante 5 pontuou: "Eu acho que na cabeça do homem é uma mulher de segunda. Entendeu? [...] A não ser que seja um homem que se apaixone extremamente por você". Mulher de segunda para a participante ganha o sentido de mulher menos verdadeira, não original e menos qualificável. Como estratégia para negarem seu interesse pelo pênis, os antigos parceiros justificam a negativa ao encontro afetivo-sexual pela negação do estatuto de mulher à participante: "eles falam que se for pra ficar com mulher mesmo eles ficam com quem já nasceu mulher" (Participante 4). Assim, a transformação corporal que se busca para socializar o corpo parece não capaz de garantir que a socialização afetiva e sexual aconteça com os antigos parceiros para algumas mulheres, podendo, nesse sentido, afetar negativamente nos processos avaliativos em relação as cirurgias realizadas.

\section{Considerações finais}

A busca pelas cirurgias de redesignação sexual parece indissociável da busca pela humanização dos corpos e pelo reconhecimento da existência nas relações sociais no gênero. Nesse sentido, a cirurgia de redesignação sexual serve à advogar sobre o direito das participantes de habitarem os lugares constituídos aos corpos mulheres com vagina na sociabilidade regulamentada sob a égide das normas de gênero. Entretanto, a vagina pareceu não ser suficiente à humanização e ao reconhecimento como mulher nas relações sociais.

Os significados atribuídos à transexualidade, como da Resolução $1.955 / 2010^{10}$, focam em possíveis sofrimentos inerentes às pessoas transexuais devido ao conteúdo patologizante dessas significações. Sob a égide desses signos binários, esvazia-se a possibilidade de crítica às normas que naturalizam a população Trans como desvio e negam a possibilidade de que elas habitem seus corpos nas relações de gênero. Bento ${ }^{14}$ e Rocon et al. ${ }^{18}$ apontam que é nos indivíduos e não nas normas de gênero que a patologização propõe in- 
tervir, como se as normas de gênero fossem biológicas e, portanto, a-históricas. Butler ${ }^{22}$ pontua que a patologização das transexualidades reforça a marginalização social dessa população, de forma que literatura permite vislumbrar a própria patologização como causa de sofrimento e adoecimento ao impedirem, via diagnóstico, o acesso aos serviços transexualizadores.

As participantes parecem não se limitar a compreender o ser mulher como estatuto biológico, apresentando o ser como desejo, de forma que ninguém nasce mulher, mas torna-se uma pela vontade de ser, que se constitui num projeto de transformação do corpo em constante avaliação sob signos de passibilidade, beleza e prazer. Nesse sentido, as intervenções corporais ao serem tomadas como estratégias de correção na direção de um corpo que se vislumbra habitar e socializar, as participantes parecem tomar a transexualidade não como doença ou desvio, mas como um lugar de passagem. A transexualidade como caminho que pode levar a produção da mulher que se deseja ser, e à outras possibilidades para experiências e normatividades de gênero não centradas no gênero binário ou na heterossexualidade compulsória.
Por fim, é preciso celebrar a existência do Processo Transexualizador no contexto brasileiro como esforço à universalização com equidade $\mathrm{e}$ integralidade do Sistema Único de Saúde, contudo, como pontua o Ministério da Saúde: “o desafio subsequente [a implantação do processo transexualizador do SUS] é a garantia do acesso a todas as pessoas que necessitam desta forma de cuidado" 24 . Os sentidos produzidos pelas equipes dos processos transexualizadores sobre gênero e transexualidade, bem como sobre os serviços oferecidos, em especial as cirurgias de redesignação sexual, tem sido importante barreira para acesso ao programa, na medida em que tais sentidos são produzidos sob a matriz binária e heterossexual para os gêneros, patologizando assim as transexualidades. Assim, buscar compreender os sentidos que a população trans produz sobre os procedimentos biomédicos para transformação do corpo, suas identidades e as relações de gênero, inserindo-os no acompanhamento multiprofissional oferecido pelos serviços transexualizadores pode ser determinante para garantia do acesso universal ao processo transexualizador do SUS.

\section{Colaboradores}

PC Rocon: concepção, delineamento e análise dos dados, redação e revisão final. F Sodré, A Rodrigues, MEB Barros e GSS Pinto: realizaram modificações e revisão final. MCBF Roseiro: revisão final. Todos aprovaram a versão final apresentada. 


\section{Referências}

1. Lionço T. Atenção integral à saúde e diversidade sexual no Processo Transexualizador do SUS. Physis 2009; 19(1):43-63.

2. Conell R, Pearse R. Gênero uma perspectiva global. São Paulo: nVersos; 2015.

3. Preciado B. Texto Yonqui. Madri: Espasa; 2008.

4. Rocon PC. Quando os corpos trans adentram o processo transexualizador: Experiências que conformam a transexualidade [dissertação]. Vitória: Universidade Federal do Espírito Santo; 2018.

5. Butler J. Problemas de gênero: feminismo e subversão da identidade. Rio de Janeiro: Civilização Brasileira; 2014.

6. Minayo MCS. O Desafio do Conhecimento: pesquisa qualitativa em saúde. São Paulo: Hucitec; 2014.

7. Castellanos MEP. A narrativa nas pesquisas qualitativas em saúde. Cien Saude Colet 2014; 19(4):10651076.

8. Vinuto J. A amostragem em bola de neve na pesquisa qualitativa: um debate em aberto. Temáticas 2014; 22(44):203-220.

9. Hess J, Rossi Neto R, Panic L, Rübben H, Senf W. Satisfaction With Male-to-Female Gender Reassignment Surgery. Dtsch Ärztebl Int 2014; 111(47):795-801.

10. Brasil. Resolução no 1.955 , de 3 de setembro de 2010 . Dispõe sobre a cirurgia de transgenitalismo e revoga a Resolução CFM no 1.652, de 2 de dezembro de 2002. Diário Oficial União 2010; 3 set.

11. Brasil. Portaria no $2.803 / \mathrm{GM}$, de 19 de novembro de 2013. Redefine e amplia o Processo Transexualizador no Sistema Único de Saúde (SUS). Diário Oficial União 2013; 19 nov.

12. Butler J. Quadros de Guerra: quando a vida é passível de luto. Rio de Janeiro: Civilização Brasileira; 2016.

13. Foucault M. Em defesa da sociedade: curso no Collège de France (1975-1976). São Paulo: Editora WMF Martins Fontes; 2010.

14. Bento B. A (re)invenção do corpo: sexualidade e gênero na experiência transexual. Rio de Janeiro: Garamond; 2006.

15. Foucault M. Os Anormais: curso no Collège de France (1974-1975). São Paulo: Editora WMF Martins Fontes; 2010.

16. Canguilhem G. O normal e o patológico. Rio de Janeiro: Forense Universitária; 2011.
17. Ferreira J. O corpo signo. In Alves PC, Minayo MCS, organizadores. Saúde e Doença: Um olhar antropológico. Rio de Janeiro: Fiocruz; 1994. p. 101-112.

18. Rocon PC, Rodrigues A, Zamboni J, Pedrini MD. Dificuldades vividas por pessoas trans no acesso ao Sistema Único de Saúde. Cien Saude Colet 2016; 21(8):2517-2525.

19. Rocon PC, Zamboni J, Sodré F, Rodrigues A, Roseiro MCFB. (Trans)formações corporais: reflexões sobre saúde e beleza. Saude Soc 2017; 26(2):521-532.

20. Borba R. $O$ (des)aprendizado de si: transexualidades, interação e cuidado em saúde. Rio de Janeiro: Fiocruz; 2016.

21. Bento B, Pelúcio L. Despatologização do gênero: a politização das identidades abjetas. Estud Fem 2012; 20(2):559-568.

22. Butler J. Desdiagnosticando o gênero. Physis 2009; 19(1):95-126.

23. Lanz L. O Corpo da roupa: a pessoa transgênera entre a transgressão e a conformidade com as normas de gênero. Curitiba: Transgente; 2015.

24. Brasil. Ministério da Saúde (MS). Processo Transexualizador no SUS (página na Internet). MS; 2017 [acessado 2018 Mar 30]. Disponível em: http://portalms. saude.gov.br/atencao-especializada-e-hospitalar/especialidades/processo-transexualizador-no-sus
Artigo apresentado em 06/02/2018

Aprovado em 26/09/2018

Versão final apresentada em 28/09/2018 